skill. For those English and American ladies who having qualified themselves by a full curriculum at home have devoted their lives to helping their suffering sisters in regions remote from civilisation by skilful practice of scientific obstetric art we feel a degree of respect and admiration which is beyond expression.

Leeds.

\section{OBSERVATIONS ON PHOSPHATURIA AND THE TREATMENT OF DISEASE BY CONVERSION.}

BY REGINALD HARRISON, F.R.C.S. ENG., PAST VICE-PRESIDENT AND HUNTERTAN PROFESSOR, BOYAI COLLEGE OF SURGEONS OF ENGLAND.

AN interesting article on the conversion of diseases in a work by Dr. John Ferriar, physician to the Manchester Royal Infirmary, entitled "Medical Histories and Reflections," published in 1795, opens with the following passage: "A disease is said to be converted when new symptoms arise in its progress which require a different designation and which either put a period to the original disorder or combining with it alter the physician's views respecting the prognostics or the method of cure." In the course of this article, which is now as suggestive as it was when written over 100 years ago, numerous illustrations from practice in support of his views will be found. I am mainly interested in one of Dr. Ferriar's references which provides an additional reason for ventilating the application of conversiou in the instance I am taking. The reference is as follows: "It must be added that general fever sometimes cures local inflammation; Mr. Hunter says he has seen a gonorrhoea extinguished by the accession of a fever." Such an experience must not be unknown to many others.

It has not infrequently been observed in the treatment of chronic urethritis and muco-purulent discharges following it, irrespectively of the internal administration of alkalies and often imperceptibly to the patient himself, that the urine became altered in character and assimilated with that known as phosphaturia. And, further, that when this change was observed the oessation of the discharge or gleet, as it is commonly called, for which the patient had originally come under treatment, usually soon followed, either spontaneously or by treatment appropriate to the phosphaturic state without apparent reference to the cause which preceded it. This casual observation raised the question whether it was possible that there was any relationship between this incident and what followed, whether, in fact, the phosphaturic state of the excretion was inimical to the existence of the infecting bacillus. The observation was made so frequently as to suggest this and led to the systematic examination of the urine and other discharges for gonococci in all persons coming under treatment for gleet more carefully and frequently than previously. From them the following conclusions appeared to be grounded.

1. That in a considerable number of instances thus designated and of undoubted specific origin there was no evidence at the time of my examination that there was anything wrong with the urine or with any urethral discharge complained of inconsistent with the phosphaturic state alone. This condition was either apparent to the eye on allowing the urine to stand for a short time in a glass vessel or was evidenced by boiling the excretion when any cloudiness which followed was immediately removed by the addition of nitric acid. Here any pus corpuscles which the microscope detected were physically explainable by the crystalline precipitates the urine contained and which were of ten present in sufficient quantities to give this excretion a semi-purnlent or opaque appearance. How or when this phosphaturic transformation took place in the history of an ordinary case of chronic infecting urethritis was not always easy to determine. In many instances which were carefully tested and microscopically examined this change appeared to mark the concluding stage of gonococcal life and was also often coincident or nearly so with the adoption of such treatment as the phosphaturic state usually requires. Further, these examinations showed how easily and frequently chosphaturia may counterfeit and be treated for a specifio urethritis and even be intensified by the remedies commonly used for the latter.

2. The second inference was that the artificial production and temporary continuance of a state of phosphaturia might be utilised in the treatment of specific gleety affections following upon gonococcal infections. To produce a urine having the prominent features of phosphaturia by the administration of alkalies--bicarbonate of potassium was generally selected for this purpose-is not a matter of much difficulty or of any detriment to the patient. The effect on the urine should be sufficient to render it responsive to the usual tests, microscopical and otherwise, by which phosphaturia is recognised, and not merely to produce an alkaline reaction to test paper. Further, it is necessary to maintain this condition for some little time, during which period all local applications should be suspended. It will usually be found after a period of ten days or so and as the phosphaturic condition gradually passes off under the influence of altered treatment and diet appropriate to this state that no signs will be found such as were previously complained of. In some instances the artificially induced phosphaturia was slow in passing off, whilst in others its presence appeared to have been too limited to effect the desired object and required repetition. On the whole, however, the results have proved satisfactory. There was a time when infecting urethritis-at all events in its earlier stages-was very generally treated by the administration of alkalies, though the reason for this was not such as I am offering. I am not at all sure in the matter of rapidity of cure that we have much improved upon this older practice by the more mechanical processes which are now often substituted.

If these observations are found in their wider application such as I have construed them a more convenient and less unpleasant method of treatment may be arrived at. They have extended over some years, and though they may not embrace the whole trath they may be read in the light of a contribution towards it.

Lower Berkeley-street, W.

H EMO-PERICARDIUM ASSOCTATED WITH SYPHILIS.

BY J. LOUGHEED BASKIN, L.R.C.P., L.R.C.S. EDIN., MEDICAI SUPERINTENDENT, FISHERTON ASYLUM; LATE DEPUTY MEDTCAL SUPERINTENDENT, DEVON COUNTY ASYLUM.

THE following case came under my notice some time ago and presents some interesting features. The patient was a married man, aged 65 years, of German nationality. When first examined by me he was fairly well nourished and well developed. His expression was gloomy and unintelligent; he was partly demented; he retained a delusion that he had been given 129 pints of medicine in one dose at a hospital. No other symptom of megalomania had been forthcoming and his general condition alternated chiefly between emotional restlessness and apathy. The skin of his entire body was very dry and slightly jaundiced. On the skin over the sternum and the interscapular region were several scars of either circular or crescentic shape, each of the size of a large pea. There was a painless swelling on the anterior border of the right tibia of the size of a florin and below this and immediately above the ankle were several small cicatrices irregular in shape; on the left leg were several ulcers with "punched-out edges" below the tuberosity of the tibia, and several similar ulcers on each forearm and extending on to the dorsum of the hand, and vaccination marks on the left upper arm. He walked slowly and with some stiffness of the hip-joints; the patellar reflexes were diminished and delayed; his grasp was feeble. Babinski's sign was absent and ankle clonus was not elicited. His right pupil was larger than the left; both reacted sluggishly to light and for the process of accommodation; the consensual reflex was present. The hearing was bad on each side; his tongue protruded in the middle line and was fleshy and grossly tremulous and furred posteriorly. He had only four teeth in his mouth (in the upper alveolus) and those were carious. His palate was unduly arched anteriorly. The cardiac sounds were irregular in rbythm; a slight bruit was audible at the first sound; his pulse was 70 and the radial and temporal arteries were tortuous and thickened. The respiratory system was healthy. His appetite was good; his intestinal movements were performed regularly. The liver was tender but no enlargement or alteration in shape or sur face was discoverable. There was a brown discolouration on the glans penis one-eighth of an inch in 
diameter; the inguinal glands were hard but easily move. able on each side. There was no urethral stricture. He was treated with antisyphilitic and cardiac remedies, chiefly sodium iodide and tincture of strophanthus, and considerable improvement occurred. The ulcers, which were dressed aseptically, healed rapidly, the swelling in the leg diminished, and the hepatic tenderness disappeared. The right inguinal glands still remained hard but his tongue showed more tremor on protrusion a few weeks after the ulcers had healed. On going into the water-closet one evening he became giddy and fainted, and though he rallied for a little time he died half an hour afterwards.

I am indebted to Dr. W. Lind Walker for his assistance in the post-mortem examination which revealed the following conditions. The basal arteries of the brain were markedly atheromatous, thickening of the arterial wall being noticeable in the anterior cerebral; no sign of cerebral or other hæmorrhage was present. The cerebral substance was so soft as to break down on touching slightly with the finger and was consequently not examined microscopically. The brain weighed 49 ounces. The right lung presented a calcified mass at the apex of about the size of a pigeon's egg. The heart weighed 11 ounces. The pericardium was distended with post-mortem clot. The coronary arteries were calcareous in character; the left one was ruptured $1 \frac{1}{2}$ inches from the aorta; at the seat of rapture was a small node of pale yellowish coloured material which extended about $1 \frac{1}{4}$ inches into the myo. cardial substance, which was hypertrophied and around it the tissue was of fibrous consistency and tough under the knife. On the pericardial aspect the necrotic changes appeared to have involved the artery which lay on the gumma; the arterial wall where ruptured presented a starshaped fissure. The aortic valve was thickened at the base of each cusp; the columnæ carneæ showed signs of fatty degeneration. The liver was congested. Nothing worth recording was found in the examination of the other organs.

Remarks. - Signs of marked distension of the pericardial sac were found on the occasion of the patient's collapse and gentle percussion revealed dulness extending up into the second left intercostal space; the cardiac sounds wer muffled and the respirations were stertorous in character the pulse was imperceptible at the wrist. When found in the heart gummata are usually multiple and often of cartilaginous-like consistency; only the one described was found in this case. Virchow has described a case in which at the same time was found syphilitic disease of the testis in the above case the testicles were not involved, though there were pigmentation on the glans penis and a caseating node in the tibia and inguinal glands. Aitken recorded in his "Science and Practice of Medicine" (seventh edition) how there used to be in the Army Medical Department at Netley two preparations showing gummata of the heartone from a soldier, 24 years of age, who had been under treatment for nine months for venereal ulcers; in the above case some of the ulcers had healed only three weeks before the patient's death. Gummata are usually found in the septum between the ventricles.

Salisbury.

\section{A CASE OF ACUTE ASCENDING PARALYSIS WITH RECOVERY.}

BY C. WILFRED VINING, M.B., B.S. LOND.,

hoUSE PHYSICIAN, ST. MARY's hospttal, PADDINGTON, W.

THE patient in the following case was a well-nourished muscular man, aged 24 years, who was admitted into St. Mary's Hospital on Dec. 2nd, 1907, under the care of Dr. Sidney P. Phillips. He felt quite well up to Nov. 28th when he experienced a feeling of weakness in the calves of his legs. He started out to work the next day, but while on the way he had to return home owing to the increasing weak. ness. On the 30th he noticed blurring of vision on reading the newspaper. On Dec 1st the weakness of his legs was still more prononnced and he could not articulate distinctly. On the following day he could not stand without assistance and his arms were also weak. He had fallen off a ladder on to his feet a week previously to the onset of the symptoms but experienced no inconvenience at the time.

On admission he was unable to walk but could just stand with assistance. There was also considerable weakness in the muscles of his arms, especially in the extensors. The muscles were flaccid but not wasted and there was an absence of all reflexes, including the palatal reflex. The respiratory, abdominal, and intercostal movements were normal. There was slight right-sided facial weakness. The external muscles of the eye were normal. The right pupil reacted sluggishly to light and to accommodation and was somewhat larger than the left. The fundi were normal. Speech was a little indistinct, apparently due to difficulty in the movements of the tongue, and there was slight aifficulty in swallowing. There was no alteration in the sensory functions except that he appeared to have lost sensation of the palate. His mouth was dirty with sordes on the lips. Cultures were obtained from the mouth and throat, but nothing resembling a diphtheritic organism was found. A lumbar puncture was performed soon after admission and 15 cubic centimetres of clear fluid with a few whitish floating particles were obtained. In this an organism having the appearance of a streptococcus was found but no growth could be obtained on culture media. The patient was given five minims of liquor strychninæ hydrochloratis every four hours and at a later period hot-air baths were administered. The muscular weakness quickly increased and on Dec. 7 th there was evidence that the diaphragm was commencing to be paralysed and chest expansion was reduced to a minimum. Rhonchi appeared in both lungs with marked cyanosis and difficulty in swallowing. There was now complete paralysis of the legs, he could barely move his arms, and there was incontinence of urine and fæces. The outlook now seemed hopeless. The pulse-rate increased, reaching 100 , and the cardiac apex passed from a point half an inch internal to the nipple to a quarter of an inch external to it. The strychnine had been stopped on Dec. 4th but it resulted in the condition becoming so much worse that on the 8 th it was resumed in doses of seven minims, quickly increased to 10 minims, every four hours, and oxygen was also adminis. tered. On the 8th there were signs of improvement, the chest movements increasing and the difficulty in swallowing lessening. From the 8 th to the $15 \mathrm{th}$ his condition remained stationary, except that some muscular wasting became evident. There were now also some slight, rather indefinite alterations in sensation over his legs, especially the right one, and he complained at times of severe pain in his knees. Sensation for heat and cold was normal. These only lasted a few days and were apparently the only sensory disturbances present during the course of the illness, except the anæsthesia of the palate mentioned above. On the 15th the diaphragm descended during quiet respiration, and from this time onwards he steadily improved. There was never any pyrexia. . On Jan. 24th he could walk without assistance, had pertect control over the sphincters, and felt very well. There was no residual paralysis, but muscular wasting of the limbs was still marked and knee-jerks were still absent. The electrical reactions taken during the course of the illness showed no reaction of degeneration, but there were reduced response to faradism and no response to galvanism. Later there was reaction to both, but less than in a normal person. During his recovery galvanism and later faradism were applied daily.

The interest of this case consisted in the recovery from what appeared to be a severe example of Landry's paralysis and which when the diaphragm showed signs of paralysis threatened to be speedily fatal. The diagnosis lay between (1) diphtheritic paralysis, (2) Landry's paralysis, and (3) a toxic paralysis affecting the anterior cornua or nerves. There was, however, no evidence or history either of diphtheria or of any exposure to such toxic influences as syphilis, gonorrhoea, lead, or alcohol, and on the whole the case seemed to correspond better with Landry's acute ascending paralysis than with any other disease. Against this diagnosis there may be urged (1) the anæsthesia of the palate and the slight sensory disturbance of the legs, and (2) the fact that the parts affected were not altogether anatomically in succession from below upwards, but in Landry's own description of the condition diminution in cutaneous sensibility over the distal parts of the limbs is mentioned and the arms and face were affected before the legs were completely paralysed. In the present case strychnine appeared to have a very bentficial effect. I am indebted to Dr. Phillips for permission to publish these notes.

Royal Institution.-At a general montbly meeting of the members of the Royal Institution held on Monday afternoon last it was announced that the managers had appointed Dr. Kenneth Robert Hay as medical officer to the Royal Institution in succession to the late Mr. Woodhouse Braine who had held the appointment for 36 years. 